Meta

Journal des traducteurs

Translators' Journal

\title{
Comment traduire « Investment » ?
}

\section{Gilles Gamas}

Volume 20, numéro 4, décembre 1975

URI : https://id.erudit.org/iderudit/002790ar

DOI : https://doi.org/10.7202/002790ar

Aller au sommaire du numéro

Éditeur(s)

Les Presses de l'Université de Montréal

ISSN

0026-0452 (imprimé)

1492-1421 (numérique)

Découvrir la revue

Citer cet article

Gamas, G. (1975). Comment traduire «Investment » ? Meta, 20(4), 317-318.

https://doi.org/10.7202/002790ar

Ce document est protégé par la loi sur le droit d'auteur. L'utilisation des services d'Érudit (y compris la reproduction) est assujettie à sa politique d'utilisation que vous pouvez consulter en ligne.

https://apropos.erudit.org/fr/usagers/politique-dutilisation/
Cet article est diffusé et préservé par Érudit.

Érudit est un consortium interuniversitaire sans but lucratif composé de l'Université de Montréal, l'Université Laval et l'Université du Québec à Montréal. Il a pour mission la promotion et la valorisation de la recherche. https://www.erudit.org/fr/ 


\section{COMMENT TRADUIRE «INVESTMENT»?}

Le terme investment est de ceux qui posent parfois des problèmes au traducteur, en raison de ses divers équivalents possibles en français : faut-il parler d'investissement, de placement, de participation ou encore d'apport en capital ? Le contexte fournit généralement la solution. Aussi étudierons-nous les équivalents d'investment selon que le contexte est économique ou financier, en traitant à part le cas de l'État.

Contexte économique: au sens économique, on entend par investissement (investment, business investment) toute action qui accroît la capacité de production. On précise parfois investissements productifs, expression qui correspond à la construction non résidentielle (bâtiments industriels et commerciaux) près, à investments in machinery and equipment. L'investissement est donc toujours réalisé en vue de la production de biens ou de services.

Notons qu'en comptabilité nationale investment in inventories se rend par investissement en stocks ou, mieux, par formation de stocks. Certains économistes considèrent en effet que tout ce qui, dans une production, n'est pas consommé relève de l'investissement. Dans leur optique, la variation des stocks fait donc partie de ce dernier, bien qu'elle ne réponde pas à la définition donnée plus haut.

La notion de rendement n'est pas sans importance ici, puisque aussi bien elle permet de régler les problèmes de choix des investissements (capital budgeting problems), mais elle n'occupe pas la place primordiale que lui accordent les financiers.

Contexte financier : dans ce cas, investment correspond plutôt à placement, terme désignant l'acquisition d'avoirs financiers (financial assets) - créances, titres - en vue de s'assurer un revenu (intérêts, dividendes) et de sauvegarder si possible le pouvoir d'achat des sommes placées. Ainsi, les actions et les obligations, les dépôts rémunérés, l'immobilier (le «placement-pierre », selon une publicité) constituent des placements. Notons que, dans ce sens, on parle souvent aussi d'investissements (ainsi pour les sociétés dites d'investissement) et toujours d'investisseurs.

Il est à remarquer que certains des avoirs mentionnés précédemment (plus précisément, les actions) peuvent représenter pour une société des participations plutôt que des placements. Une entreprise détient une participation dans une autre lorsqu'elle possède une certaine partie des fonds propres (equity) de cette dernière. L'anglais emploie dans ce sens des expressions où entre soit investment, soit equity (par exemple equity interest). Ainsi, dans le manuel de l'Institut canadien des comptables agréés (ICCA), intercorporate investments correspond à participations et portion of the equity à pourcentage de participation. La participation se distingue du placement en ceci que le détenteur en attend une plus-value et, généralement, un droit de regard sur la marche de l'entreprise plutôt qu'un revenu (sans qu'il y 
ait, bien évidemment, incompatibilité entre les deux). Fait significatif, le plan comptable général français classe les titres de participation dans les valeurs inımobilisées et les titres de placement dans les comptes financiers. Par exemple, les actions de filiales détenues par une société mère constituent pour cette dernière des participations, de même que les titres acquis par une banque d'affaires dans une entreprise qui sollicite son concours à long terme pour se développer. Par contre, le portefeuille-titres d'une banque de dépôts entre dans la catégorie des placements. (Dans le sens de placement ou de participation, investments peut donc se rendre, si le contexte s'y prête, par titres ou portefeuilles-titres.)

L'État, lui aussi, réalise des investissements, prend des participations et possède un portefeuille. Aucun de ces termes ne convient cependant dans un cas particulier, que nous étudions maintenant.

Contexte des opérations de l'État: les comptes publics mentionnent les apports ou dotations en capital, expression qui désigne les capitaux mis par l'État à la disposition de ses entreprises (entre autres bénéficiaires) autrement que sous forme de prêts ou d'avance. On relève ainsi, dans le rapport de la Cour des comptes au président de la République française, les « apports en capital aux entreprises publiques » et les «intérêts des avances, prêts et dotations en capital » (à rapprocher, dans les Comptes publics du Canada, de l'expression advances, loans and investments).

Nous noterons en guise de conclusion que nous avons seulement essayé de guider le traducteur en définissant les grands domaines d'emploi du terme investment, sans chercher à en recenser tous les équivalents possibles dans tel ou tel contexte particulier. Le traducteur ajoutera ainsi à sa liste mise de fonds, intérêts et autres expressions de sens voisin.

Gilles Gamas 